\title{
Case Report -I
}

Lymphoma Associated Haemophagocytic Syndrome A Diagnostic Trap

\author{
MARY NANDINI SINGH, RAJALAKSHMI T, MARJORIE CORREA, USHA KINI \\ AND GIRIJA SINGH,
}

\begin{abstract}
Haemophagocytic syndrome (HPS) may occur in association with a variety of bacterial, viral (mostly EBV), fungal and parasitic infections, auto immune diseases and rarely, neoplasms. The outcome depends on the underlying cause, with malignancies carrying a poor prognosis. A 55 year old man presented with fever, generalized weakness and progressive abdominal distention of one month duration. He had significant lymphadenopathy and hepatosplenomegaly. Bone marrow showed marked fibrosis. Cervical lymph node biopsy showed an extensive haemophagocytic response with strikingly atypical cells in the background. A diagnosis of T-cell lymphoma was established on morphologic and immunohistochemical basis.
\end{abstract}

\section{INTRODUCTION}

Haemophagocytic syndrome (HPS) is a rare disorder of immune regulation. It is characterized clinically by fever, pancytopenia, splenomegaly, coagulation abnormalities, hyperferritinemia and haemophagocytosis in the bone marrow, liver or lymph nodes., ${ }^{1,2}$ This syndrome has been described in association with a variety of bacterial, viral, fungal and parasitic diseases, autoimmune diseases and rarely, neoplasms such as Lymphomas. ${ }^{1,2,3}$

Departments of Pathology, St. John's Medical College,

Bangalore - 560 034. India

Correspondence to: RAJALAKSHMI T,

Email:rajtiru@hotmail.com
The term haemophagocytosis describes the pathologic finding of activated macrophages engulfing haemopoietic cells (i.e. erythrocytes, leucocytes, platelets and their precursor cells) in the lymph nodes, bone marrow, liver or spleen. The treatment of haemophagocytic syndrome is difficult and in most cases associated with malignancy, the evolution is rapidly fatal. ${ }^{2}$

CASE : A 55 year old man presented with intermittent high-grade fever, generalized weakness, jaundice and blackish stools for 20 days. Clinical examination revealed marked pallor, jaundice, hepatosplenomegaly, bilateral cervical and axillary lymphadenopathy. A provisional diagnosis of haematologic malignancy was made. Initial investigations revealed pancytopenia ( $\mathrm{Hb} 5.2 \mathrm{gm} \%$, WBC 600 cells $/ \mathrm{cmm}$. Platelets $52,000 / \mathrm{cmm}$ ) and markedly elevated liver enzymes, particularly Alkaline Phosphatase (974 U/L). Serum LDH was $566 \mathrm{U} / \mathrm{L}$. Ultrasound abdomen showed features suggestive of portal hypertension. Bone marrow aspiration was a dry tap. Trephine biopsy of the bone marrow showed marked fibrosis. Blood, urine and CSF cultures showed no growth.

A biopsy of the cervical lymph node was done. The lymph node showed marked hemophagocytic response, as evidenced by large macrophages containing ingested red cells, lymphoid cells and nuclear debris (Fig 1). On careful observation, a few atypical cells were seen scattered in the background. These cells were large, pleomorphic with hyperchromatic, 
convoluted, irregular nuclei, and scant cytoplasm, reminiscent of lymphoid cells (Fig 2). On closer examination, these cells were also seen within the cytoplasm of macrophages. A morphologic diagnosis of haemophagocytic response with a suspicion of associated Lymphoma was made.

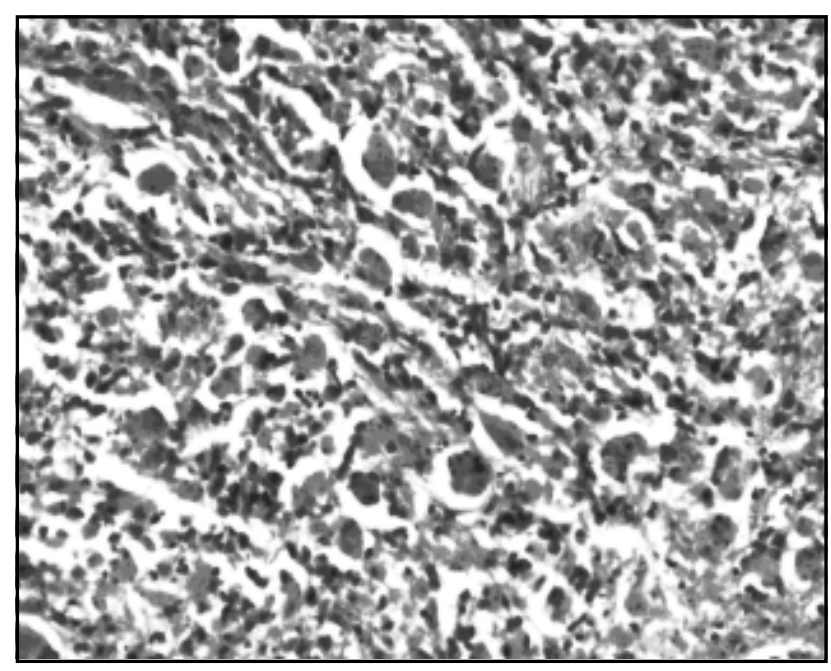

Fig 1. Lymph node showing sheets of macrophages engulfing haematolymphoid cells and debris within their cytoplasm. (H\&E, x 200)

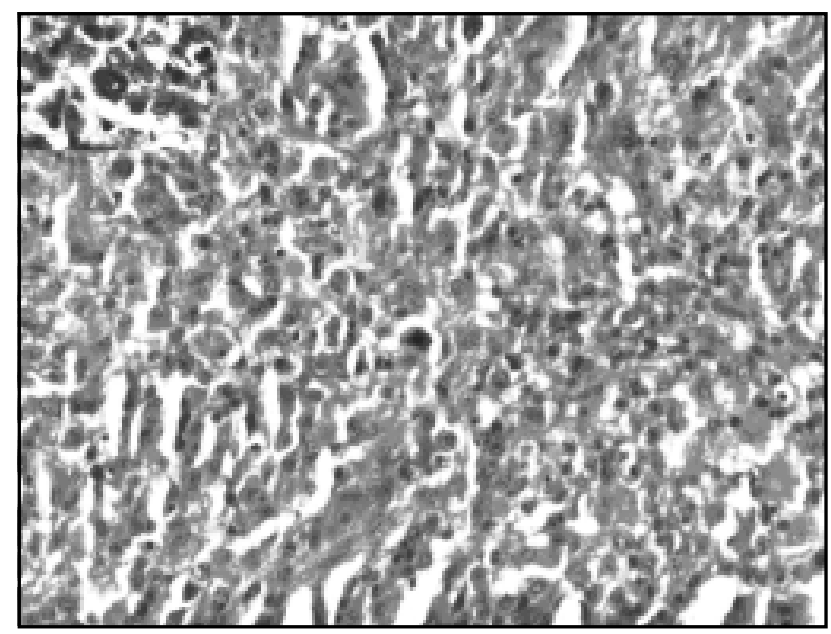

Fig 2. Scattered atypical cells in the background, with inset showing nuclear pleomorphism and coarse chromatin. (H\&E, x 200, x 400)
On immunohistochemistry, the atypical lymphoid cells were positive for CD3 and negative for CD20, indicating a T-cell origin. The CD68 stain highlighted the macrophages with engulfed material. A negative Pancytokeratin ruled out a metastatic carcinoma. Immunostain for EBV Latent Membrane Protein (LMP-1) was negative. A final diagnosis of haemophagocytic response complicating a T-cell lymphoma was made.

\section{CLINICAL COURSE}

At admission, the patient was started on antibiotics. Leucovorin was given, but with little response. His WBC count fell to 300 per $\mathrm{cmm}$, while platelet count was 7000 per $\mathrm{cmm}$. Around the $10^{\text {th }}$ day following admission, he developed coagulation defects, as evidenced by a prothrombin time of $>1 \mathrm{~min}$ and APTT of 119". He was started on Steroids, but did not respond. He worsened around the $12^{\text {th }}$ day following admission; he developed metabolic acidosis, deteriorating renal function and multi-organ dysfunction. He succumbed to the illness on the $14^{\text {th }}$ day following admission.

\section{DISCUSSION}

Haemophagocytic syndrome (HPS) is a rare disorder of immune regulation. This syndrome, which has also been referred to as Histiocytic Medullary Reticulosis, Haemophagocytic Lymphohistiocytosis or Macrophage Activation Syndrome, was first described in 1939 by Scott and Robb-Smith. ${ }^{3}$ The clinical features include fever, pancytopenia, splenomegaly, coagulation abnormalities, hyperferritinemia and haemophagocytosis in the bone marrow, liver or lymph nodes. ${ }^{1,2}$ Owing to the overlap of these symptoms with other infections and haematologic dyscrasias, it is a diagnosis easily missed. Primary HPS, usually seen in children, is well defined and carries a better prognosis.

Secondary HPS is not a single entity, but a response pattern accompanying a host of underlying conditions. The associations include viral infections (EBV, commonly), fungi, 
bacteria, parasites and auto immune diseases. ${ }^{1}$ Rarely, they may be the manifestation of a malignancy such as a lymphoma. ${ }^{3}$ The lymphomas commonly associated with HPS include cutaneous T-cell lymphomas, T/NK cell lymphomas, angiocentric lymphomas, erythrophagocytic $\mathrm{T}$ gamma lymphoma, anaplastic large cell lymphoma (ALCL), $\mathrm{T}$ - acute lymphoblastic leukemia ALL, and rarely, B cell lymphomas. ${ }^{4,5,6}$ A case of Hodgkin's lymphoma has also been described with HPS. ${ }^{7}$ Finally, HPS may also be encountered as a phenomenon in malignant histiocytosis. ${ }^{2}$ In patients with lymphomas, HPS may occur during the course of the disease or may be the initial manifestation. Takahashi et al have marrow, liver or spleen. A likely mechanism for this is the aberrant cytokine response, such as TNF- $\alpha$ and Interferons by clonal expansion of T lymphocytes or virus-infected cells. ${ }^{1}$ In the CD56-expressing (NK cell) lymphomas, direct cytotoxicity by MHC-unrestricted tumour cells has been proposed as a means. ${ }^{5}$

In contrast to the primary and infectionassociated HPS, where recovery is possible, LAHS carries a poor prognosis. Takahashi et al, in their series of 142 cases of LAHS, have documented a median survival of 242 days and 69 days for $B$ and $T$ cell lymphomas, respectively. ${ }^{8}$ In another series of 26 cases, 21 patients died due to multi-organ dysfunction and disseminated intravascular coagulation (DIC), with a median survival of 83 days. ${ }^{9}$

Table1. Proposed diagnostic criteria for Lymphoma-associated Haemophagocytic syndrome (LAHS). (adapted from reference 8)

1. High fever for more than a week (peak $\left.38.5^{\circ} \mathrm{C}\right)$

2. Anemia $(\mathrm{Hb}<9 \mathrm{gm} / \mathrm{dl})$ or thrombocytopenia $(<100,000 \mathrm{i} / \mathrm{L})$

3. $\quad$ a) $\mathrm{LDH}=2 \times$ normal

b) Hyperferritinemia $=1000 \mathrm{ng} / \mathrm{dl}$

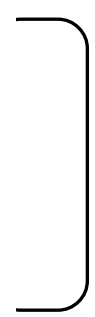

Two out of four criteria

c) Hepatosplenomegaly on CT/US/MRI

d) $\mathrm{FDP}=10 \mathrm{ig} / \mathrm{ml}$

4. Hemophagocytosis in BM/spleen/liver

5. No evidence of infection

6. Histopathologically confirmed lymphoma

When criteria 1 to 5 are present for two weeks and glucocorticoid/ã-globulin therapy is not effective, a diagnosis of probable LAHS can be made and chemotherapy be started

FDP-fibrinogen degradation product

proposed criteria for the diagnosis of Lymphoma-associated haemophagocytic syndrome (LAHS). ${ }^{8}$ (Table 1 ).

On morphology, HPS is characterised by activated macrophages engulfing haemopoietic cells (i.e. erythrocytes, leucocytes, platelets and their precursor cells) in the lymph nodes, bone
The main histologic differential diagnosis to be borne in mind here is a malignant histiocytosis, in which the engulfing macrophages display cytologic atypia. ${ }^{10}$ The features that favour a lymphoma are: Segregation of lymphomatous component from phagocytes, Cytologic atypia in lymphoma cells, no cytologic atypia in phagocytes and confirmation by 
Immunophenotyping. Rarely, the two malignancies may co-exist. ${ }^{11}$

This case underlines the importance of suspecting HPS with the described constellation of clinical features. Early biopsy facilitates correct diagnosis and prompt initiation of specific therapy, depending on the underlying cause. To the pathologists, it pays to study with extra care the background cells whenever a hemophagocytic reaction is encountered. Very often, an underlying malignancy is obscured. Morphology alone may not suffice in proving the neoplastic origin in such cases and it is essential to use immunohistochemical/molecular markers judiciously to establish the diagnosis. Early recognition is crucial as they warrant aggressive therapy.

\section{REFERENCES:}

1. Fisman DN. Hemophagocytic syndromes and infection. Emerg Infect Dis. 2000;6(6):601-8.

2. Linn $Y C$, Tien SL, Lim LC, et al. Haemophagocytosis in bone marrow aspirate-a review of the clinical course of 10 cases. Acta Haematol. 1995;94(4):182-91.

Falini B, Pileri S, De Solas I, et al. Peripheral T-cell lymphoma associated with hemophagocytic syndrome. Blood. 1990;15:75(2):434-44.
4. Artigues Barceló A, Ferragut Reus M, Sánchez C, Amengual I, Matanza I, Sanz Parras MS. Haemophagocytic syndrome and cutaneous T-cell lymphoma An Med Interna. 2004;21(3):131-4.

5. Jang KA, Choi JH, Sung KJ, et al. Primary CD56 + nasal-type T/natural killer-cell subcutaneous panniculitic lymphoma: presentation as haemophagocytic syndrome. Br J Dermatol. 1999 Oct; 141(4):706-9.

6. Shimazaki C, Inaba T, Shimura K, et al. B-cell lymphoma associated with haemophagocytic syndrome: a clinical, immunological and cytogenetic study. Br J Haematol. 1999;104(4):672-9.

7. Hasselblom $S$, Linde $A$, Ridell B. Hodgkin's lymphoma, Epstein-Barr virus reactivation and fatal haemophagocytic syndrome. J Intern Med. 2004;255(2):289-95.

8. Takahashi N, Chubachi A, Miura I, Nakamura S, Miura AB. Lymphoma-associated hemophagocytic syndrome in Japan. Rinsho Ketsueki. 1999;40(7):5429.

9. Takahashi N, Chubachi A, Kume $M$ et al. A Clinical Analysis of 52 Adult Patients With Hemophagocytic Syndrome: The Prognostic Significance of the Underlying Diseases. Int J Hematol. 2001;74: 209-213.

10. Jaffe ES, Costa.J, Fauci AS, et al. Malignant lymphoma and erythrophagocytosis simulating malignant histiocytosis. Am J Med,1983;75(5):741-749.

11. O'Brien CJ, Child JA, Stark A, Lauder I, Bird CC. Concurrent T-cell lymphocytic lymphoma and malignant histiocytosis. Histopathology. 1985:9(9):977-86. 